\title{
Family Planning Advice and Postpartum Contraceptive Use Among Low-Income Women in Mexico
}

By Sarah L. Barber

Sarah L. Barber is research fellow, Institute of Business and Economic Research, Haas School of Business, University of California, Berkeley,

CA, USA, and visiting scholar, National Institute of Public Health, Cuernavaca, Mexico.
CONTEXT: In Mexico, family planning advice has been incorporated into the clinical guidelines for prenatal care. However, the relationship between women's receipt of family planning advice during prenatal care and subsequent contraceptive use has not been evaluated.

METHODS: Data were collected in 2003 and 2004 in 17 Mexican states from 2,238 urban low-income women postpartum. Participating women reported on prenatal services received and contraceptive use. Logistic and multinomial logistic regression models evaluated whether receiving family planning advice during prenatal care predicted current contraceptive use, after quality of care in the community, service utilization, delivery characteristics, household socioeconomic characteristics, and maternal and infant characteristics were controlled for.

RESULTS: Overall, $47 \%$ of women used a modern contraceptive method. Women who received family planning advice during prenatal care were more likely to use a contraceptive than were those who did not receive such advice (odds ratio, 2.2). Women who received family planning advice had a higher probability of using condoms (relative risk ratio, 2.3) and IUDs (5.2), and of undergoing sterilization (1.4), than of using no method.

CONCLUSIONS: Integrating family planning advice into prenatal care may be an important strategy for reaching women when their demand for contraception is high.

International Family Planning Perspectives, 2007, 33(1):6-12
Quality family planning services are an important means of increasing knowledge about contraception and acceptance of effective methods, as well as influencing method choice. ${ }^{1}$ In the 1970s, low contraceptive prevalence and poorly functioning health systems existed in many developing countries; in such settings, vertical delivery systems and community-based health workers were essential to the rapid increase of contraceptive knowledge and prevalence. Over time, however, the mode of family planning service delivery has evolved. Today, many family planning programs have been integrated into formal health delivery structures for a number of reasons. These include the success of earlier programs in sustaining contraceptive demand, the relatively high cost of community-based delivery, declining budgets for family planning and the need to increase efficiency in supervision and management. ${ }^{2-4}$

A review of trials on integrated service delivery, however, found no consistent benefit of integration on patient outcomes, costs or health system performance in less developed settings, although the number of studies was small and their designs limited comparisons. ${ }^{4}$ Nonetheless, two of the trials demonstrated that integration of family planning service delivery results in increased contraceptive use or uptake. ${ }^{5,6}$

Because the demand for contraception fluctuates over the course of a woman's reproductive life, the timing of service delivery must be considered as part of any integration effort. The postpartum period is particularly important be- cause appropriate birthspacing can improve maternal and infant health. ${ }^{7}$ Moreover, the demand for effective contraception may be high immediately after delivery. Previous cross-sectional studies report positive associations between maternal and child health service use $e^{8-10}$ and subsequent contraceptive use. In addition, prenatal services offer the opportunity to reach women who would be the primary target of family planning services. Because of this, global strategies have used prenatal care as an entry point in the delivery of core reproductive health services, including family planning. ${ }^{11}$

The site of the present study is Mexico, a middle-income country of 106 million people, more than three-quarters of whom reside in urban areas. ${ }^{12}$ During the 1980s, the Mexican government established community-based distribution programs to help reduce population growth rates through the rapid introduction of modern contraceptives. ${ }^{13}$ These programs were integral to a doubling of the contraceptive prevalence rate from 30\% in 1976 to $60 \%$ in 2005. ${ }^{14,15}$ Although community-based health workers were essential to delivering family planning services to remote and rural populations in the 1970s, their role has diminished with urbanization and increased access to primary health facilities. Taking an integrated approach to service delivery, the Ministry of Health has incorporated family planning counseling into the national clinical guidelines for prenatal care. ${ }^{16}$ The relationship between women's receipt of family planning advice during prenatal care and 
subsequent contraceptive use, however, has not been evaluated. In this study, data from surveys conducted in 2003 and 2004 in urban Mexico are used to determine whether receipt of family planning advice during prenatal care predicts contraceptive use.

\section{METHODS}

Data

The data used in this study are from the 2003 and 2004 rounds of the Encuesta de Evaluación Urbana (ENCELURB). These two surveys were commissioned by the Mexican government to evaluate the urban implementation of the Oportunidades poverty reduction program. The surveys were carried out in the 17 states in which the program operated. For the 2003 round, 16,125 households were surveyed; in the 2004 round, 15,021 (90\% and $88 \%$ of targeted households, respectively). The refusal rate was 4\% in 2003 and 2\% in 2004. Failure to locate targeted households was the most frequently cited reason for not completing interviews (9\% in 2003 and 8\% in 2004).

The current study used data from the survey's fertility module, which was administered to women of reproductive age. The analyses focused on reports from 2,436 women who had had a live birth within 12 months before the survey interview. Postpartum, therefore, was defined as less than one year after delivery. For 87 women who were interviewed in both survey rounds, one observation was randomly selected for inclusion. The 127 women who did not receive prenatal care were omitted from the analyses. In addition, 27 women reported a multiple birth; these women were omitted because they may have received a higher level of care and the experience of having a multiple birth may affect decisions about contraceptive use. With these exclusions, the analyses focused on 2,238 urban women.

\section{Variables}

- Dependent variables. The study focused on two main outcomes that measured contraceptive use. The first was a dichotomous variable indicating use of any modern contraceptive method (condoms, the pill, an IUD, an injectable or sterilization).

The second main outcome was a multiple outcome dependent variable identifying the six method categories: no method, the pill, condoms, an IUD, an injectable or sterilization. A very small proportion of women (2\%) used traditional methods; these women were combined into the category of no method. None of the women surveyed used sponges, gels or diaphragms. One woman reported using implants; she was included with injectable users because both methods are hormonal and require periodic visits to a health provider. The vast majority of women within the sterilization category underwent female sterilization (97\%), and the remainder reported male sterilization or hysterectomy. Because the categories are not mutually exclusive and some women reported using condoms in addition to other methods, use is categorized by efficacy (sterilization, then hormonal methods, IUDs and the exclusive use of condoms). FIGURE 1. Percentage distribution of low-income women
interviewed within one year postpartum, by current contraceptive method, urban Mexico, 2003 and 2004

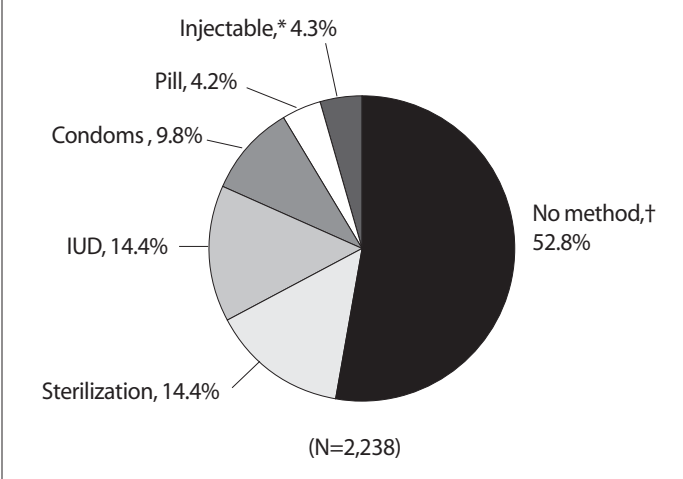

*Includes one woman who was using implants. tIncludes $2 \%$ of women who used traditional methods.

- Key explanatory variables. Participants were asked if their prenatal care had included each of 12 specific services recommended in the national clinical guidelines. ${ }^{* 16}$ This set of questions provided the information for the key explanatory variable: receipt of advice about family planning during prenatal consultations.

Advice about family planning, however, may be correlated with overall health care in the community. To correctly predict the importance of advice relative to overall quality of care, a community quality variable was generated using the information about the 12 recommended prenatal services women received. The positive responses were summed, and a variable was generated that represented the proportion of the 12 procedures received. However, care received may be affected by systematic differences related to the women's characteristics. To correct for this potential bias, we estimated a regression that predicted the quality variable for each woman on her individual, household, demographic and community characteristics (defined below). From this regression, a community fixed effect was generated to capture the average quality of care in the community, purged of differences in individual, household and demographic characteristics. Using the community fixed effect, a dummy variable was generated to identify communities with high quality of health care, defined as one standard deviation above the mean. In absolute terms, high-quality care communities are those in which women received more than $78 \%$ of the recommended procedures on average.

- Individual and household characteristics. All regression models controlled for characteristics related to prenatal care and delivery and household socioeconomics, in addition to maternal and infant factors. Factors related to prenatal care and delivery included the number of prenatal visits, delivery location and provider qualifications for delivery. Control-

*The 12 services are collection of blood and urine samples; documentation of bleeding and discharge; measurement of blood pressure, weight and uterine height; provision of tetanus toxoid immunization, iron supplements, and advice about family planning and breast-feeding; and instruction in use of the health card. 


\begin{tabular}{|c|c|c|c|}
\hline Characteristic & $\begin{array}{l}2003 \\
(\mathrm{~N}=1,181)\end{array}$ & $\begin{array}{l}2004 \\
(\mathrm{~N}=1,057)\end{array}$ & $\begin{array}{l}\text { Average } \\
(\mathrm{N}=2,238)\end{array}$ \\
\hline \multicolumn{4}{|c|}{ Prenatal care/delivery } \\
\hline Received family planning advice & 66.6 & $74.1^{* *}$ & 70.2 \\
\hline High-quality care in community & 52.0 & 57.4 & 54.6 \\
\hline No. of prenatal visits & 5.7 & $6.4^{* *}$ & 6.0 \\
\hline \multicolumn{4}{|l|}{ Delivery location } \\
\hline Social security facility & 20.2 & 19.2 & 19.7 \\
\hline Other government facility & 49.0 & 52.2 & 50.5 \\
\hline Private facility $\dagger$ & 15.9 & 17.8 & 16.8 \\
\hline Home & 14.9 & 10.8 & 13.0 \\
\hline \\
\hline $\begin{array}{l}\text { Household monthly expenditure } \\
\text { (log of pesos per capita) }\end{array}$ & 5.9 & $5.8^{*}$ & 5.9 \\
\hline Indigenous-speaking household & 14.0 & $10.7^{*}$ & 12.4 \\
\hline \multicolumn{4}{|c|}{ Household head } \\
\hline Education (yrs.) & 5.8 & 5.8 & 5.8 \\
\hline Married & 87.2 & 86.1 & 86.7 \\
\hline Age (yrs.) & 36.3 & $37.7^{* *}$ & 37.0 \\
\hline No. of household members & 6.1 & $6.7^{* *}$ & 6.4 \\
\hline Household has radio and TV & 54.5 & 57.4 & 55.9 \\
\hline \multicolumn{4}{|l|}{ Maternal and infant } \\
\hline 1 & 21.9 & $28.3^{* *}$ & 24.9 \\
\hline $2-4$ & 65.7 & 61.6 & 63.8 \\
\hline$\geq 5$ & 12.4 & 10.1 & 11.3 \\
\hline Education (yrs.) & 6.5 & $7.0 * *$ & 6.7 \\
\hline Married & 86.5 & 86.5 & 86.5 \\
\hline Age (yrs.) & 26.0 & 25.6 & 25.8 \\
\hline Currently breast-feeding & 39.0 & 44.6 & 41.6 \\
\hline Infant's age (mos.) & 5.9 & 5.8 & 5.9 \\
\hline \multicolumn{4}{|c|}{ Participation in social welfare program } \\
\hline \multicolumn{4}{|c|}{ Oportunidades } \\
\hline \multirow{2}{*}{\multicolumn{4}{|c|}{ Papilla (nutritional }} \\
\hline & & & \\
\hline supplements) & 20.6 & $14.0^{* *}$ & 17.5 \\
\hline Despensa (food packages) & 3.8 & 3.9 & 3.8 \\
\hline Desayunos (breakfast program) & 8.2 & 6.5 & 7.4 \\
\hline \multicolumn{4}{|l|}{ Procampo (cash transfer } \\
\hline for farmers) & 0.8 & 0.3 & 0.5 \\
\hline
\end{tabular}

ling for the number of visits aimed to differentiate between the quality and the quantity of care. The number of visits is expressed in the regressions as a natural logarithm.

The survey identified 14 delivery locations, which can be divided into three major categories: clinics and hospitals in the social security sector; government services for the uninsured, including Oportunidades and Ministry of Health facilities; and private facilities, including clinics, hospitals and noninstitutional solo practitioners.

Household socioeconomic controls included household wealth, indigenous status, marital status and age of the household head, household size, and whether the household had both a television and radio. Household wealth is measured as monthly household expenditures on food and nonfood items; it is expressed as a logarithm and per capita. Expenditures are considered more accurate in measuring household wealth for populations with informal or sea- sonal employment. ${ }^{17}$ A dummy variable identifying indigenous populations was included because they represent a vulnerable group in Mexico. An indigenous household was identified by whether the woman interviewed speaks an indigenous language at home. Marital status may affect contraceptive use; the head of household is categorized as married as opposed to being single, divorced, separated or widowed. Variables measuring the age and education of the household head were included because contraceptive use may be affected by characteristics of a husband or parent. ${ }^{18}$ Last, the availability of a radio and television was included because they may increase exposure to family planning public service messages and awareness of their availability.

Maternal and infant factors included in all regressions were maternal marital status, age and education, the number of previous pregnancies and whether the woman was breast-feeding at the time of the survey. The number of previous pregnancies was expressed as a categorical variable identifying one, two to four, and five or more previous pregnancies. Also included was infant age in months at the time of the survey to control for variations in postpartum acceptance of methods related to infant age. Lastly, the analyses included dummy variables representing the 2004 survey to control for time trends as well as household participation in one of five public social welfare programs. In some cases, participation in such programs requires obtaining medical care and health education; it also identifies households with temporary financial or other vulnerabilities that can tip near-poor households into poverty, such as job loss, catastrophic illness or weather fluctuations that may affect agricultural income. The programs included the Oportunidades poverty reduction program, several food supplementation programs (Desayuno breakfast program, Despensa food packages and Papilla nutritional supplements) and Procampo cash subsidies for farmers.

\section{Analyses}

The first logistic regression model assessed the association between contraceptive use and receipt of family planning advice during prenatal care. The odds ratios and confidence intervals are reported for advice received, quality in the community, the number of prenatal visits and the control variables. Second, we predicted the use of specific methods in a multinomial logistic regression model; no method was used as a baseline. The relative risk ratios and confidence intervals for the key variable of family planning advice received are reported, in addition to community quality and the number of prenatal visits. The number of prenatal visits is expressed as a natural logarithm in the regressions; however, in the text, the absolute change in the odds of contraceptive use is reported. The analyses focused on the relationships between receipt of family planning advice and contraceptive use rather than trying to fully explain the factors associated with use of each method. Therefore, in the final table, each control variable is included in the regressions but only the joint significance of these controls is noted in the text. 


\section{RESULTS}

\section{Sample Characteristics}

Fewer than half of the women surveyed in 2003 and 2004 (47\%) were practicing contraception (Figure 1, page 7). Among current users, the majority relied on IUDs or sterilization, and about one in five reported the exclusive use of condoms (not shown). The pill and the injectable each accounted for fewer than one in 10 current users.

Significant differences in prenatal care can be observed between 2003 and 2004: The proportion of women who reported that they had received family planning advice during prenatal visits increased from $67 \%$ to $74 \%$ (Table 1). Women in 2004 reported making an average of 6.4 prenatal care visits, significantly more than the 5.7 reported in 2003.

No significant change occurred in delivery characteristics between the two years. For both years, about one in five delivered in social security facilities, and approximately half of the sample delivered in Ministry of Health or other government facilities. Deliveries in private institutions accounted for $17 \%$ of the total.

The households of the respondents in 2004 were slightly poorer than those in 2003, as measured by monthly household expenditure. There was a lower proportion of indigenous households in 2004, and household heads in 2004 were older than those in 2003; each household had more members in 2004. Women in the 2004 sample had had more education than those in the 2003 sample. On average, 12\% of households were indigenous-speaking, and the heads of households were 37 years old and had had fewer than six years of formal education. The great majority of household heads were married, as were most women interviewed.

In 2003, 22\% of the women had experienced one prior pregnancy; in 2004, 28\% had. On average, the women surveyed were 26 years old, and had had nearly seven years of education. The number of years of education was higher among the 2004 survey participants. On average, 42\% were breast-feeding, and the age of their infants was about six months. More than half of households were participating in the Oportunidades poverty reduction program, and 18\% were in the Papilla nutritional supplement program; in 2004, there was a slight decline in the number of households participating in these programs.

\section{Multivariate Analyses}

Women who received family planning advice during prenatal care were significantly more likely to use a contraceptive postpartum than were those who did not (odds ratio, 2.2-Table 2). Women living in communities with highquality care were more likely to use a method than were those in communities with lower quality of care (1.4). In addition, women who had a higher number of prenatal visits were more likely than those with fewer prenatal visits to use contraceptives; in absolute terms, the effect is equivalent to a $4 \%$ increase in odds with each additional visit.

Institutional delivery was an important predictor. Women delivering in government or private facilities were more likely to use a contraceptive postpartum than were women who

\begin{tabular}{|c|c|}
\hline Characteristic & Odds ratio \\
\hline \multicolumn{2}{|l|}{ Prenatal care/delivery } \\
\hline Received family planning advice & $2.15^{* *}(1.73-2.67)$ \\
\hline High-quality care in community & $1.35^{* *}(1.07-1.70)$ \\
\hline No. of prenatal visits (In) & $1.39 * *(1.12-1.73)$ \\
\hline \multicolumn{2}{|l|}{ Delivery location } \\
\hline Social security facility & $3.13^{* *}(2.14-4.57)$ \\
\hline Other government facility & $2.60 * *(1.87-3.62)$ \\
\hline Private facility & $1.91^{* *}(1.30-2.80)$ \\
\hline Home (ref) & 1.00 \\
\hline \multicolumn{2}{|l|}{ Household socioeconomic } \\
\hline $\begin{array}{l}\text { Household monthly expenditure } \\
\text { (In pesos per capita) }\end{array}$ & $1.25^{* *}(1.05-1.50)$ \\
\hline Indigenous-speaking household & $0.60 * *(0.44-0.81)$ \\
\hline \multicolumn{2}{|l|}{ Household head } \\
\hline Education† & $1.00(0.97-1.03)$ \\
\hline Married & $1.29(0.93-1.79)$ \\
\hline Age† & $0.99(0.98-1.00)$ \\
\hline No. of household members & $1.03(0.98-1.07)$ \\
\hline Household has radio and TV & $1.13(0.93-1.36)$ \\
\hline \multicolumn{2}{|l|}{ Maternal and infant factors } \\
\hline \multicolumn{2}{|l|}{ No. of pregnancies } \\
\hline 1 & $0.75^{*}(0.58-0.97)$ \\
\hline $2-4$ (ref) & 1.00 \\
\hline$\geq 5$ & $0.90(0.64-1.29)$ \\
\hline Educationt & $1.01(0.98-1.04)$ \\
\hline Married & $1.88^{* *}(1.37-2.60)$ \\
\hline Aget & $1.01(0.99-1.03)$ \\
\hline Currently breast-feeding & $1.00(0.82-1.21)$ \\
\hline Infant's aget & $1.09^{* *}(1.06-1.12)$ \\
\hline \multicolumn{2}{|l|}{ Year } \\
\hline 2003 (ref) & 1.00 \\
\hline 2004 & $0.96(0.80-1.16)$ \\
\hline
\end{tabular}

delivered at home (odds ratios, 1.9-3.1). As expected, the odds of contraceptive use were positively associated with household wealth (1.3), being married (1.9) and older age of infant (1.1). Negative associations are noted for women from indigenous-speaking households (0.6) and those experiencing their first live birth (0.8). Included but not shown are the controls for household participation in any of five social welfare programs; together, however, these variables were not jointly significant.

Having received family planning advice during prenatal care predicted increased odds of the use of condoms (relative risk ratio, 2.3-Table 3, page 10) and IUDs (5.2), as well as having undergone sterilization (1.4). Family planning advice was not significant in predicting the odds of using the pill or injectables.

Living in communities with high quality of care was associated with increased odds of IUD use (relative risk ratio, 1.5) and sterilization (1.6). In addition, the number of prenatal visits was positively associated with use of condoms, injectables and sterilization. The year of interview was not significantly associated with method use, indicating no change over time. The four sets of control variables for delivery location, household socioeconomics, maternal and 


\begin{tabular}{|c|c|}
\hline Method and characteristic & Relative risk ratio \\
\hline \multicolumn{2}{|l|}{ Condom vs. no method } \\
\hline Received family planning advice & $2.29^{* *}(1.56-3.36)$ \\
\hline High-quality care in community & $1.42(0.89-2.26)$ \\
\hline No. of prenatal visits $(\log ) \dagger$ & $1.56^{* *}(1.13-2.15)$ \\
\hline Year $=2004$ & $1.04(0.79-1.38)$ \\
\hline \multicolumn{2}{|l|}{ Pill vs. no method } \\
\hline Received family planning advice & $1.30(0.76-2.22)$ \\
\hline High-quality care in community & $1.29(0.85-1.97)$ \\
\hline No. of prenatal visits $(\log ) \dagger$ & $0.88(0.57-1.36)$ \\
\hline Year $=2004$ & $0.93(0.60-1.46)$ \\
\hline \multicolumn{2}{|l|}{ IUD vs. no method } \\
\hline Received family planning advice & $5.15^{* *}(3.26-8.13)$ \\
\hline High-quality care in community & $1.51^{* *}(1.09-2.09)$ \\
\hline No. of prenatal visits $(\log ) \dagger$ & $1.24(0.91-1.68)$ \\
\hline Year $=2004$ & $0.91(0.69-1.21)$ \\
\hline \multicolumn{2}{|l|}{ Injectable vs. no method } \\
\hline Received family planning advice & $1.67(0.98-2.86)$ \\
\hline High-quality care in community & $0.65(0.38-1.09)$ \\
\hline No. of prenatal visits $(\log ) \dagger$ & $1.75^{*}(1.05-2.93)$ \\
\hline Year $=2004$ & $1.17(0.80-1.71)$ \\
\hline \multicolumn{2}{|l|}{ Sterilization vs. no method } \\
\hline Received family planning advice & $1.42^{*}(1.06-1.91)$ \\
\hline High-quality care in community & $1.64^{* *}(1.18-2.30)$ \\
\hline No. of prenatal visits $(\log ) \dagger$ & $1.50 *(1.05-2.14)$ \\
\hline Year $=2004$ & $0.93(0.69-1.26)$ \\
\hline
\end{tabular}

infant characteristics and household participation in social welfare programs were jointly significant in this model (not shown).

\section{DISCUSSION}

The findings that receiving family planning advice and higher quality of care predicts contraceptive use are consistent with those of previous studies that show relationships between maternal and child health services and contraceptive use,$^{8-10}$ or between technical quality and contraceptive use ${ }^{19-21}$ or prevalence. ${ }^{22}$ Previous studies in Mexico also illustrate the importance of family planning advice and counseling. Potter and colleagues noted in 1981 that fear of negative health consequences was the main impediment to contraceptive acceptance in rural Mexico. ${ }^{13}$ The same issues remain relevant today, even in urban Mexico, where there is widespread access to basic services. National surveys in 1995 cited limited knowledge as the reason for not using contraceptives among 9\% of urban and $19 \%$ of rural women. ${ }^{14}$ Even larger proportions of women in these surveys (32\% of urban and $43 \%$ of rural women) reported fear of side effects, especially during breast-feeding. A smaller, hospital-based study of postpartum contraception found that $32 \%$ of women wished to delay use. ${ }^{18}$ The authors attribute this finding to knowledge of the reduced risk of pregnancy because of lactational amenorrhea, and fear that contraceptives might harm the health of the moth- er or infant. These findings together suggest that even when populations have access to services, it is important for health care providers to offer advice about available modern methods, to offset fears about negative side effects and to enable fully informed choice. However, the capacity of health workers to provide counseling and advice should also be addressed.

In the current study, having received family planning advice predicted use of IUDs, condoms and sterilization. Many women in the sample relied on public health services as a source of prenatal care. This finding may reflect, therefore, the public and social security health systems' emphasis on IUDs and sterilization as the most effective postpartum contraception. Indeed, Potter notes that early government policies in Mexico continue to have a strong influence on the types of contraceptives promoted today in the Mexican public health system. ${ }^{23}$ The finding that high quality of care in the community independently predicted IUD use and sterilization is consistent with the notion that the policies within the overall service environment play a very important role in promoting specific methods.

Family planning advice was significant in predicting the probability of using condoms. It is likely that condoms were provided during routine prenatal visits and promoted among women who were undecided about their fertility intentions. Overall quality of care in the community, however, was not significantly related to condom use, probably reflecting that condoms can be readily purchased without prescriptions. The number of prenatal visits predicted the use of both condoms and the injectable. A higher number of visits may imply greater exposure to the formal health system and willingness to accept advice that influences uptake.

It is noteworthy that high-quality care in the community was a significant predictor of the odds of sterilization. Because sterilization is a permanent method that requires confidence in the health system, overall quality of care likely influences the decision to undergo the procedure. This suggests that advice for sterilization may be most effective if integrated within the broader health system. Previous authors have noted that facility quality may influence contraceptive use among women who have never used or have discontinued use because of poor-quality services. ${ }^{20} \mathrm{Hav}$ ing access to high-quality services may increase confidence in the health system and encourage utilization.

Neither family planning advice nor quality predicted the use of the pill or an injectable. A very small proportion of women in the sample used either the pill or an injectable ( $4 \%$ each). The sample was drawn from poor urban populations, and the effort and cost of regularly using these methods may be a consideration; this requires further investigation. Lack of data precluded analyses including prices, although the costs of obtaining the pill or an injectable affect contraceptive behavior. ${ }^{9}$ The pill generally requires more effort than other methods because users have to remember to take it daily. Because of the additional effort it requires and its associated higher use-failure rates, the pill may not be encouraged by health staff. In addition, the availability 
of the pill was not assessed; lack of supplies may be a contributing factor.

\section{Study Limitations and Strengths}

This study has several limitations. The data describe lowincome urban women. Low-income populations in Mexico have relatively high rates of fertility ${ }^{14}$ and are not representative of the population as a whole. Urban populations are likely to have greater exposure to the formal health system than rural populations, who may be more reliant on traditional sources of care. Data about family planning and quality of care are limited in this study. Information is available about whether family planning advice was received, but the comprehensiveness of the family planning advice was not assessed. Quality in this study is measured by adherence to clinical guidelines, which varies widely across diverse settings. ${ }^{24}$ Previous studies have developed broad indices of quality, including structural elements, technical quality and perceptions. ${ }^{20,22}$ These indices, however, do not consider that different elements of quality may have distinct effects on behavior and health outcomes. Other studies have used respondents' perceived quality to predict contraceptive use. ${ }^{25}$ However, perceptions may be based on factors such as prior health service use and expectations, socioeconomic status and coexisting medical conditions. ${ }^{26}$ Thus, perceptions can be difficult to interpret and do not correlate well with objective quality measures. ${ }^{27}$ Reports about the receipt of specific procedures are less likely to reflect prior expectations and individual factors. Questions about prenatal procedures performed were asked at the same time as questions about contraceptive methods used. This suggests that recall bias may be a limitation-women who accepted contraceptives may have recalled family planning advice more accurately than women who did not accept contraceptives. ${ }^{20}$

The finding that the delivery environment was important in predicting contraceptive use is consistent with qualitative data from rural Mexico. ${ }^{28}$ The present study did not, however, assess the promotion of contraception in the delivery environment, which may be particularly important for sterilization. The possible bias in selective allocation of public resources was not addressed in this study. ${ }^{29}$ However, prenatal care is composed largely of a set of routine procedures indicated for all women and thus varies little by region. In addition, data were collected from the same communities in 2003 and 2004.

Although the same communities were targeted for interviews, a different set of women responded to the fertility module each year. These data therefore do not inform about continuity of method use. However, the Hawthorne effect is minimized because the panel is composed of communities, and women in the sample were interviewed only once. Although the study controls for maternal, infant, household and community characteristics, it did not collect information about prior contraceptive use and knowledge-important factors in method choice and use. ${ }^{20}$

Selection bias is minimized because the sample is composed of women who obtained prenatal care during their pregnancy-not only women who sought family planningand prenatal care is nearly universal in this urban population. Although the 3\% of women who did not obtain prenatal care were significantly poorer and less educated than the rest of the sample, this omission is not expected to bias the results.

\section{Conclusion}

Providing information about family planning as a part of prenatal care is an important means of increasing postpartum contraceptive use in urban Mexico. Relatively low levels of method use in this setting may be addressed by increasing the proportion of providers who offer family planning advice during prenatal care, and strengthening their capacity to advise about the safety and efficacy of hormonal methods. These findings may be relevant in other settings that are considering ways to integrate family planning advice and counseling into general health services.

\section{REFERENCES}

1. RamaRao $S$ and Mohanam $R$, The quality of family planning programs concepts, measurements, interventions, and effects, Studies in Family Planning, 2003, 34(4):227-248

2. Barberis M and Harvey PD, Costs of family planning programs in fourteen developing countries by method of service delivery, Journal of Biosocial Science, 1997, 29(2):219-233.

3. Prata $\mathrm{N}$ et al., Revisiting community-based distribution programs: are they still needed? Contraception, 2005, 72(6):402-407.

4. Briggs CJ, Capdegelle P and Garner P, Strategies for integrating primary health services in middle- and low-income countries: effects on performance, costs and patient outcomes, Cochrane Database of Systematic Reviews, 2001, (4):CD003318.

5. Huntington D and Aplogan A, The integration of family planning and childhood immunization services in Togo, Studies in Family Planning, 1994, 25(3): 176-183.

6. Taylor CE and Parker RL, Integrating PHC services: evidence from Narangwal, India, Health Policy and Planning, 1987, 2(2):150-161.

7. Levitt $C$ et al., Systematic review of the literature on postpartum care: selected contraception methods, postpartum Papanicolaou test, and rubella immunization, Birth, 2004, 31(3):203-212

8. Seiber EE et al., Maternal and child health and family planning service utilization in Guatemala: implications for service integration, Social Science E Medicine, 2005, 61(2):279-291.

9. Hotchkiss DR et al., The effects of maternal-child health service utilization on subsequent contraceptive use in Morocco, Journal of Biosocial Science, 1999, 31(2):145-165.

10. Zerai A and Tsui AO, The relationship between prenatal care and subsequent modern contraceptive use in Bolivia, Egypt and Thailand, African Journal of Reproductive Health, 2001, 5(2):68-82.

11. World Health Organization (WHO), Reproductive Health Strategy to Accelerate Progress Towards the Attainment of International Development Goals and Targets, Geneva: WHO, 2004.

12. United Nations, World Population Prospects: The 2004 Revision, <http://esa.un.org/unpp>, accessed Feb. 7, 2007.

13. Potter JE, Mojarro $O$ and Nuñez L, The influence of health care on contraceptive acceptance in rural Mexico, Studies in Family Planning, 1987, 18(3):144-156.

14. Gómez de León J and Hernández D, Poverty and Contraceptive Use in Rural Mexico: Poverty, Fertility and Family Planning, Mexico City: Committee for International Cooperation in National Research in Demography, 1998.

15. United Nations Population Fund (UNFPA), State of World Population 
2005: The Promise of Equality-Gender Equity, Reproductive Health and the Millennium Development Goals, New York: UNFPA, 2005.

16. Ministry of Health, Norma Oficial Mexicana, NOM-007-SSA2-1993, Atención a la mujer durante el embarazo, parto y puerperio a recién nacidos. Criterios y procedimientos para la prestación del servicio, Mexico City: Ministry of Health, 1993.

17. Deaton A, The Analysis of Household Surveys: A Microeconomic Approach to Policy Development, Baltimore, MD, USA: Johns Hopkins University Press, 1997.

18. Romero-Gutiérrez G et al., Postpartum contraceptive acceptance in León, Mexico: a multivariate analysis, European Journal of Contraception and Reproductive Health Care, 2003, 8(4):210-216.

19. Lei ZW et al., Effect of pretreatment counseling on discontinuation rates in Chinese women given depot-medroxyprogesterone acetate for contraception, Contraception, 1996, 53(6):357-361.

20. RamaRao S et al., The link between quality of care and contraceptive use, International Family Planning Perspectives, 2003, 29(2):76-83.

21. Cotten $\mathrm{N}$ et al., Early discontinuation of contraceptive use in Niger and the Gambia, International Family Planning Perspectives, 1992 18(4):145-149.

22. Mensch B, Arends-Kuenning M and Jain A, The impact of the quality of family planning services on contraceptive use in Peru, Studies in Family Planning, 1996, 27(2):59-75.

23. Potter JE, The persistence of outmoded contraceptive regimes: the cases of Mexico and Brazil, Population and Development Review, 1999 25(4):703-739.

24. Barber SL, Quality of care in developing countries: its importance, measurement, and selected quality improvement programs and policies, Working Paper, Institute of Business and Economic Research, University of California, Berkeley, CA, USA, 2007.

25. Koenig MA et al., The influence of quality of care upon contraceptive use in rural Bangladesh, Studies in Family Planning, 1997, 28(4): 278-289.

26. Brook RH, McGlynn EA and Skekelle P, Defining and measuring quality of care: a perspective from U.S. researchers, International Journal for Quality in Health Care, 2000, 12(4):281-295.

27. Speizer IS and Bollen KS, How well do perceptions of family planning service quality correspond to objective measures? evidence from Tanzania, Studies in Family Planning, 2000, 31(2):163-177.

28. Feldman B, unpublished data, Boston, MA, USA: Harvard School of Public Health, 2006.

29. Molyneaux JW and Gertler PJ, The impact of targeted family planning programs in Indonesia, Population and Development Review, 2000, 26(Suppl.):61-85.

\section{RESUMEN}

Contexto: En México se han incorporado los servicios de consejería en planificación familiar a las directrices clínicas de atención prenatal. Sin embargo, no se ha evaluado la relación entre el servicio de consejería durante la atención prenatal y el uso posterior de anticonceptivos.

Métodos: Los datos fueron recopilados en 2003 y 2004 en 17 estados mexicanos de 2,238 mujeres en estado de postparto y de bajos ingresos, residentes en centros urbanos. Las entrevistadas suministraron datos sobre los servicios prenatales recibidos y su uso de anticonceptivos. Mediante modelos de regresión logística multinominal, se evaluó si la consejería en planificación familiar durante la atención prenatal actuaba como un mecanismo de predicción del uso actual de anticonceptivos, después de controlar la calidad de la atención en la comunidad, la utilización de los servicios, las características del parto, la condición socioeconómica del hogar, y las carac- terísticas de la madre y del recién nacido.

Resultados: En general, el 47\% de las mujeres usaban un método anticonceptivo moderno. Las mujeres que habian recibido consejería sobre planificación junto con su la atención prenatal eran más proclives a usar un anticonceptivo que aquellas que no habían recibido este servicio (razón de momios, 2.2). Las mujeres que recibieron consejería en planificación familiar tenían mayores probabilidades de usar el condón (razón de riesgo relativo, 2.3), de aceptar el DIU (5.2) y de someterse a la esterilización (1.4), relativo a no usar ningún método.

Conclusiones: La integración de la consejería en planificación familiar a la atención prenatal puede ser una importante estrategia para atender a las mujeres cuando es elevada su demanda de servicios anticonceptivos.

\section{RÉSUMÉ}

Context: Au Mexique, le conseil de planification familiale a été incorporé aux directives cliniques des soins prénatals. Le rapport entre la réception de ce conseil durant la période de soins prénatals et la pratique contraceptive ultérieure n'a cependant pas été évalué.

Méthodes: Les données ont été recueillies en 2003 et 2004, dans 17 états du Mexique, auprès de 2.238 femmes en post-partum à revenus faibles des milieux urbains. Les participantes ont été interrogées sur les services prénatals reçus et sur leur pratique contraceptive. Des modèles de régression logistique et logistique multinomiale ont servi à évaluer si la réception d'un conseil de planification familiale dans le cadre des soins prénatals permettait de prédire la pratique contraceptive courante, en tenant compte de la qualité des soins assurés dans la communauté, de l'utilisation des services, des caractéristiques de prestation, des caractéristiques socioéconomiques des ménages et des caractéristiques maternelles et infantiles.

Résultats: Dans l'ensemble, $47 \%$ des femmes pratiquaient une méthode contraceptive moderne. Celles qui avaient reçu un conseil de planification familiale dans le cadre de leurs soins prénatals en étaient plus susceptibles que celles qui n'avaient pas bénéficié de ce conseil (rapport de probabilités, 2,2). Pour les premières, la probabilité d'usage du préservatif (rapport des risques relatifs, 2,3) ou du stérilet $(5,2)$ et de recours à la stérilisation $(1,4)$ s'est avérée supérieure à celle de n'utiliser aucune méthode.

Conclusions: L'intégration du conseil de planification familiale aux prestations de soins prénatals peut offrir une stratégie importante d'accès aux femmes lorsque la demande de contraception est élevée.

\section{Acknowledgments}

This research was supported by grant TW006084-03 from the Fogarty International Center, National Institutes of Health. The data were collected by the National Institute of Public Health in Mexi$c o$, with funding from the Oportunidades program of the Mexican Ministry of Social Development and the Inter-American Development Bank. The author is grateful for comments from Becca Feldman, Lisa deMaria and Dominic Montagu.

Author contact: barber@haas.berkeley.edu 